\title{
Physical Properties of Chitosan Films Obtained after Neutralization of Polycation by Slow Drip Method
}

\author{
Jaiber Humberto Rodriguez Llanos, Luci Cristina de Oliveira Vercik, Andrés Vercik \\ Basic Sciences Department, Faculty of Animal Science and Food Engineering, University of São Paulo, \\ Pirassununga, São Paulo, Brazil \\ Email: jrodriguezll@usp.br, jaiber.rodriguez@gmail.com
}

Received 17 September 2015; accepted 18 October 2015; published 21 October 2015

Copyright (C) 2015 by authors and Scientific Research Publishing Inc.

This work is licensed under the Creative Commons Attribution International License (CC BY). http://creativecommons.org/licenses/by/4.0/

(c) (i) Open Access

\begin{abstract}
The development of new materials from biodegradable constituents is enticing for applications in bioelectronics and biomedicine, due to their considerable durability, versatility and biodegradability. The present work aims to determine the chemical and physical properties of chitosan membranes after neutralization of the polycation solution. This work was divided into two stages: solubilization and neutralization. In the first stage, the chitosan was solubilized with three different concentrations of acetic acid $(1 \%, 0.8 \%$ and $0.5 \%)$ in order to evaluate whether the acid affected the physical-chemical properties of the films. In the second stage, the chitosan polycation was neutralized with two strong bases ( $\mathrm{NaOH}$ and $\mathrm{KOH})$ using three different molar concentrations, by the slow drip method for obtaining films with $\mathrm{pH}$ values close to neutrality. The characterization of the membranes obtained from casting method showed that the different concentrations of acetic acid did not affect the physical-chemical properties of the films. In contrast, the neutralization process did affect their properties, and in particular, different behaviors were observed depending on the type of base used for neutralization. More ductile and plasticity were obtained in the films when the polycation was neutralized with $\mathrm{KOH}$, whereas the films neutralized with $\mathrm{NaOH}$ exhibited a more fragile behavior.
\end{abstract}

\section{Keywords}

Biodgradavel Film, Chitosan, Hydrogel, Mechanical Properties, Swelling

\section{Introduction}

The use of biological materials in the development of components for electronic application has attracted consi-

How to cite this paper: Llanos, J.H.R., de Oliveira Vercik, L.C. and Vercik, A. (2015) Physical Properties of Chitosan Films Obtained after Neutralization of Polycation by Slow Drip Method. Journal of Biomaterials and Nanobiotechnology, 6, 276291. http://dx.doi.org/10.4236/jbnb.2015.64026 
derable interest among scientists because of the advantages it offers to the device such as: simple processing, low manufacturing cost, versatile molecular design and the ability to control physicochemical properties. A number of devices including electrochemical biosensors, load cells, electroluminescent devices and Schottky diodes were fabricate and tested using conductive polymers [1]. New materials and components for industrial applications should possess special physical characteristics such as durability, resistance to handling and versatility of use.

Most polymers demonstrate a resistance to the passage of electric current, exhibiting the behavior of electrical insulators. Chitosan is the deacetylated form of chitin, which is a linear type of biopolymer acetyl-D-glucose with the ability to act as a proton conductive matrix. This property is a direct result of the lone pair associated with the amine and hydroxyl groups within the chitosan monomer; making the material a suitable candidate for a solid electrolyte polymer [2]-[6].

Chitosan is a natural polymer that has unique properties, primarily its non-toxicity, biodegradability and biocompatibility [6]. It can be a suitable matrix for the development of biosensors by positioning of the membranes and immobilizing biological materials (enzymes such as horseradish peroxidase or HRP) on the surface of the matrix. The chitosan powder is solubilized in a solution of acetic acid (1\%). As a result, the membrane has a pH value of approximately 4.3, which can affect the enzymatic kinetics negatively since maximum enzymatic activity of HRP occurs for $\mathrm{pH}$ values in the range of 5 - 6 [7].

The development of enzymatic biosensors demands materials with certain characteristics for the support of the immobilization of enzymes. In the case of biopolymer matrices, it is necessary to remove traces of solvent in the film, other than the free hydroniums present in the polymer matrix, because of a $\mathrm{pH}$ value near neutrality and bioreceptors with a high fixing ability [8]. To do so, the neutralization process of the membrane removes residual acid and regenerates the $\mathrm{NH} 2$ groups of the chitosan making the hydrophilic surface of the film and cell compatible [9].

This study aims to characterize the physical-chemical behavior, and eventual industrial applications, of chitosan membranes neutralized, obtained from the solubilization of chitosan powder in three concentrations of acetic acid ( $1 \%, 0.8 \%$ and $0.5 \%)$. The solution of polycation will be neutralized by the method of slow dripping, employing two strong bases, sodium hydroxide $(\mathrm{NaOH})$ and potassium hydroxide $(\mathrm{KOH})$ in three molar concentrations $(0.5,1$ and $5 \mathrm{M})$.

\section{Materials and Methods}

\subsection{Materials}

Chitosan derived from crab shell with a deacetylation degree greater than $85 \%$ and average molecular weight, was purchased from Sigma Co. (Brazil). Glacial acetic acid was purchased from NEOBIO (Brazil). Sodium and Potassium hydroxide (analytical grade) was purchased from SYNTH (Brazil). All other reagents were local products of analytical grade.

\subsection{Production of Neutralizing Solutions}

Neutralizing solutions of sodium and potassium hydroxide were produced from the dissolution of bases in deionized water $\left(18.2 \mathrm{~m} \Omega \cdot \mathrm{cm} @ 25^{\circ} \mathrm{C}\right)$ in three molar concentrations $(0.5,1$ and $5 \mathrm{M})$.

\subsection{Production of Buffer Solution}

The phosphate buffered saline (PBS) solution was produced according to a previously published report [10]. Buffer solutions with different $\mathrm{pH}$ 's (pH5 and $\mathrm{pH} 9$ ) were prepared from the mixture of hydrated monosodium phosphate $\left(\mathrm{NaH}_{2} \mathrm{PO}_{4} \mathrm{H}_{2} \mathrm{O}\right)$ and disodium phosphate heptahydrate $\left(\mathrm{Na}_{2} \mathrm{HPO}_{4} 7 \mathrm{H}_{2} \mathrm{O}\right)$. For the preparation of phosphate buffer solution at $\mathrm{pH} 5,1.361 \mathrm{~g}$ of $\mathrm{NaH}_{2} \mathrm{PO}_{4} \mathrm{H}_{2} \mathrm{O}$ and $0.036 \mathrm{~g}$ of $\mathrm{Na}_{2} \mathrm{HPO}_{4} 7 \mathrm{H}_{2} \mathrm{O}$ were used; for the preparation of the solution at $\mathrm{pH} 90.01 \mathrm{~g}$ of $\mathrm{NaH}_{2} \mathrm{PO}_{4} \mathrm{H}_{2} \mathrm{O}$ and $2.660 \mathrm{~g}$ of $\mathrm{Na}_{2} \mathrm{HPO}_{4} 7 \mathrm{H}_{2} \mathrm{O}$ were used for $100 \mathrm{ml}$ of solution.

\subsection{Obtaining Films}

\subsubsection{Production of Chitosan Polycation}

The powdered chitosan $(1 \% \mathrm{w} / \mathrm{v})$ with a degree of deacetylation of $85 \%$ and an average molecular weight sup- 
plied by Aldrich Chemical Company Ltd. (Brazil) was solubilized in deionized water with different concentrations of acetic acid (1\%, $0.8 \%$ and $0.5 \%)$ under constant stirring until complete dissolution of the chitosan. The viscous solution of the polycation was filtered by vacuum using a filter with a pore size of $1.2 \mu \mathrm{m}$ in order to remove insoluble particles and impurities present in the chitosan powder; the process of filtered were performed one time.

The polycationic solutions were classified according to acetic acid concentration used, and type/concentration of base used to neutralize the polycation. Table 1 illustrates the sorting method and the name assigned to each sample, where white corresponds to the control, or no-neutralized, sample.

\subsubsection{Neutralization of the Chitosan Polycation}

The chitosan polycation was neutralized by slow drip of neutralizing solution $(\mathrm{NaOH}$ and $\mathrm{KOH}$ in different molar concentration) at the rate of one drop of solution per minute (1 drop/minute) until reaching a $\mathrm{pH}$ of 6.0 under constant agitation. According to reported by [6] [11], the pK of chitosan polycation is around 6.3 due to the presence of amino groups. The neutralization process and slow dripping can be observed in Figure 1.

\subsubsection{Production of Chitosan Films}

The neutralized films were produced by casting technique. The solubilization of chitosan in acetic acid was performed with constant stirring, using $1 \mathrm{~g}$ quitosana/100 $\mathrm{ml}$ of solution (acetic acid at various concentrations). The polycation chitosan was neutralized under constant stirring with continuous $\mathrm{pH}$ control due to the constant drip of neutralizing solution, which was previously obtained from the solubilization of bases in deionized water at specific molar concentrations $(0.5,1$ and $5 \mathrm{M})$. The neutralization process brought the $\mathrm{pH}$ of the polycation to 6.0. After neutralizing the polycation, the solution was kept in an ultrasound bath (Ultra Cleane $1400^{\mathrm{a}}$, Unique) for 5 minutes. The solutions were spread on petri dishes (Bioplass) with the same amount of mass ( $25 \mathrm{~g}$ ) to ensure a constant thickness. The solutions dispersed and settled, and then the petri dishes were dried in a forced circulation oven (MA 037, Marconi) at $30^{\circ} \mathrm{C}$ for 48 hours. After that time, the films were placed in desiccators with silica gel until the characterization process.

\section{Table 1. Classification of samples to be processed.}

\begin{tabular}{cccccccc}
\hline & \multicolumn{4}{c}{ Neutralizing solution NaOH } & \multicolumn{3}{c}{ Neutralizing solution KOH } \\
\hline $\begin{array}{c}\text { Concentration of } \\
\text { acetic acid used }\end{array}$ & White & $0.5 \mathrm{M}$ & $1 \mathrm{M}$ & $5 \mathrm{M}$ & $0.5 \mathrm{M}$ & $1 \mathrm{M}$ & $5 \mathrm{M}$ \\
\hline $\mathrm{HAc} 1 \%$ & $\mathrm{Qs}_{\mathrm{W} 1}$ & $\mathrm{QsSo}_{1} 0.5$ & $\mathrm{QsSo}_{1} 1.0$ & $\mathrm{QsSo}_{1} 5.0$ & $\mathrm{QsPo}_{1} 0.5$ & $\mathrm{QsPo}_{1} 1.0$ & $\mathrm{QsPo}_{1} 5.0$ \\
$\mathrm{HAc} 0.8 \%$ & $\mathrm{Qs}_{\mathrm{W} 2}$ & $\mathrm{QsSo}_{2} 0.5$ & $\mathrm{QsSo}_{2} 1.0$ & $\mathrm{QsSo}_{2} 5.0$ & $\mathrm{QsPo}_{2} 0.5$ & $\mathrm{QsPo}_{2} 1.0$ & $\mathrm{QsPo}_{2} 5.0$ \\
$\mathrm{HAc} 0.5 \%$ & $\mathrm{Qs}_{\mathrm{W} 3}$ & $\mathrm{QsSo}_{3} 0.5$ & $\mathrm{QsSo}_{3} 1.0$ & $\mathrm{QsSo}_{3} 5.0$ & $\mathrm{QsPo}_{3} 0.5$ & $\mathrm{QsPo}_{3} 1.0$ & $\mathrm{QsPo}_{3} 5.0$ \\
\hline
\end{tabular}

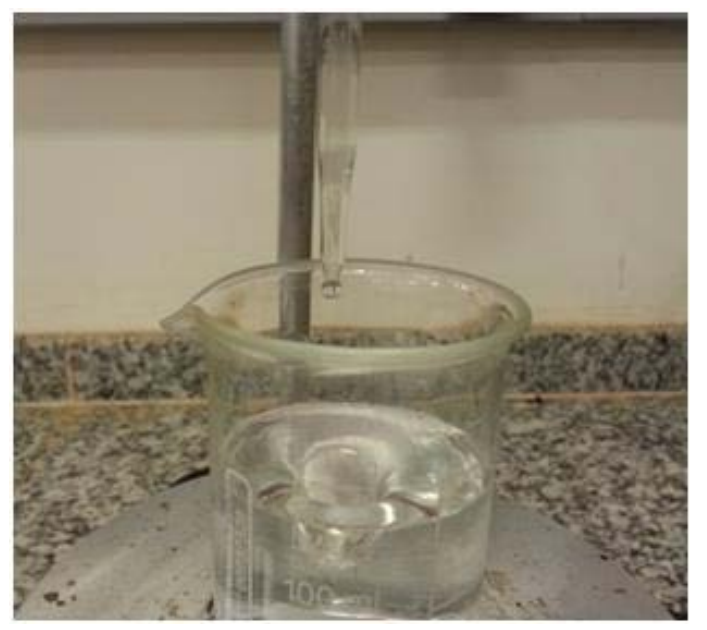

Figure 1. Slow drip of neutralizing solution for neutralization process of chitosan polycation. 


\subsection{Characterization of Neutralized Films}

\subsubsection{Ultraviolet Spectroscopy (UV-Vis)}

The chitosan neutralized polycation was analyzed from the changes presented in the links in the presence of bases, for analyzed this changes respect to standard samples was employed a Beckman Coulter DU 800, thereby colloids were treatment for a range of wavelengths between 200 and $800 \mathrm{~nm}$. Each determination was done in triplicate.

\subsubsection{FT-IR Spectroscopy}

The films obtained after the interaction between the chitosan polycation and the neutralized solutions were evaluated with a Perkin Elmer spectrophotometer (Spectrum One FT-IR) equipped with UATR according to a previously published report [12]. Scans (16 scans in point) were performed in the spectral range of $400-4000 \mathrm{~cm}^{-1}$ with a resolution of $2 \mathrm{~cm}^{-1}$. The results were collected and treated with Spectrum One software (Spectrum One, version 5.3).

\subsubsection{X-Ray Diffraction}

The neutralized films crystallinity was compared with the standard film crystallinity from the X-ray diffraction (Rigaku Geigerflex Powder Diffractometer) with Ni-filtered, Cu radiation, operated at $30 \mathrm{kV}$ and $30 \mathrm{~mA}$. Diffraction patterns were recorded over a range of diffraction angles $2 \theta=5^{\circ}$ to $25^{\circ}$ with a scan rate of $1^{\circ}(2 \theta)$ per minute and a step size of $0.1^{\circ}(2 \theta)$.

\subsubsection{Thickness}

The thickness of the films was determined using a digital micrometer (Mitutoyo) with range of $0-25 \mathrm{~mm}$ and accuracy of $0.001 \mathrm{~mm}$. Values are presented as the average of ten measurements made randomly along each sample evaluated by performing triplicate for each film type.

\subsubsection{Swelling}

The films samples were cut into a $10 \times 10 \mathrm{~mm}$ square. The dried and stabilized samples, which were in a desiccator for 72 hours, were removed and weighed (AUY220 Shimadzu, analytical scale) to determine the weight of the dry sample. After weighing, the samples were immersed in solutions of phosphate buffer with respective $\mathrm{pH}$ values of 5 and 9 . To determine the percentage of swelling, it was necessary to collect data for a period of 72 hours beginning data collection every 15 minutes in an hour, and every hour until at least 4 hours had passed. After this time, the collection of date was made every 4 hours over 8 hours and then performed every 8 hours over the first 24 hours. Collecting data every 24 hours during the 72 hours of the test is finished.

To establish the percentage of swelling it is necessary to relate the dry weight of the sample to the weight of the hydrated sample (Equation (1)). This was achieved by taking the samples from the swelling solution every time data collection began and removing excess moisture from the film surface with pre-moistened filter paper, ensuring only the absorption of moisture from the surface of the film.

$$
S(t)=\left(W_{t} / W_{0}-1\right) * 100
$$

where $S(t)$ is the percent of swelling, $W_{(t)}$ the final weight and $W_{0}$ the initial film weight.

\subsubsection{Mechanical Properties}

The mechanical properties of the films were evaluated by Stress-Strains curves (The Young's modulus E, the strain at break, the stress at break and energy required to fracture) using a texturometer TA.XT2i (TA Instrumens).

To determine the mechanical properties by tensile stress-strain test, the films were cut into strips of $15 \mathrm{~mm}$ wide and $80 \mathrm{~mm}$ long; then the films were stored in a desiccator with silica gel for seven days. The strips were fixed in the grips of a texturometer with an initial height of $50 \mathrm{~mm}$ (lo) and stretched using a crosshead speed of $0.9 \mathrm{~mm} / \mathrm{s}$, the films were stretched to failure, generating a stress (MPa) strain (\%) curve. The analysis was performed in triplicate.

\subsubsection{Scanning Electron Microscopy}

The surface and internal microstructure, of chitosan films were analyzed by the scanning electron microscope 
(SEM) (Hitachi, TM30000) at $15 \mathrm{kV}$. For analysis, the samples were pre-conditioned in a desiccator with silica gel under vacuum. To analyze the internal microstructure the films were freeze-fractured after immersion inliquid nitrogen.

\section{Results and Discussion}

\subsection{Neutralization of Chitosan Polycation}

The process of neutralizing the polycation without reaching the pKa (6.3) of chitosan [6] [11] using the sodium and potassium bases in different concentrations by the slow drip method produced films with physical and chemical properties that can have a range of uses. Among these is developing an ideal polymeric matrix for the immobilization of biological receptors, which are the base of biosensors. The solutions of the polycation showed no significant difference regarding their color, since they all had similar transparency when different concentrations of acetic acid were used in the solubilization of chitosan and when different concentrations of the bases were used to neutralize polycation. In contrast, the films did show differences, since neutralized films with sodium have a white color whereas the films neutralized with potassium exhibit a transparency similar to films without treatment. This difference may be associated with different ionic radius of sodium $\left(\mathrm{Na}^{+}=0.95 \AA\right)$ and potassium $\left(\mathrm{K}^{+}=1.33 \AA\right)$, present in the solutions of neutralization. Furthermore, the white color in the films obtained from the chitosan polycation neutralized with solutions of sodium hydroxide is linked directly to formation of sodium acetate on the membrane surface, while the membranes obtained from the polycation neutralized with potassium could form the acetate within the membrane structure. The color of the films is shown in Figure 2.

\subsection{Characterization of Neutralized Chitosan Films}

\subsubsection{Ultraviolet Spectroscopy (UV-Vis)}

The solubilized chitosan polycation in three concentrations of acetic acid and neutralized with two different bases with three molar concentrations were characterized by UV-vis spectroscopy in a wavelength range of 200 to $600 \mathrm{~nm}$. The spectra obtained are shown in Figure 3, characterized by an increase in absorption near the 240 $\mathrm{nm}$ wavelength directly related to the increase in concentration of acetic acid to solubilize the chitosan. The observed displacement in wavelength may be associated with a variation in crystallinity within the polymer matrix. The band of $225 \mathrm{~nm}$ in the UV-vis spectrum is attributed to ionic linkages $(\eta \rightarrow \pi)$ that are directly affected by the base used for neutralization of the polycation chitosan when it is solubilized with a percentage of acetic acid greater than or equal to $1 \%$. The absorption near to $280 \mathrm{~nm}$ is attributed to unsaturated bonds of covalent linkages $(\pi \rightarrow \pi)$ principally C-O, which increases the absorption intensity with increased chitosan concentration [13] [14].

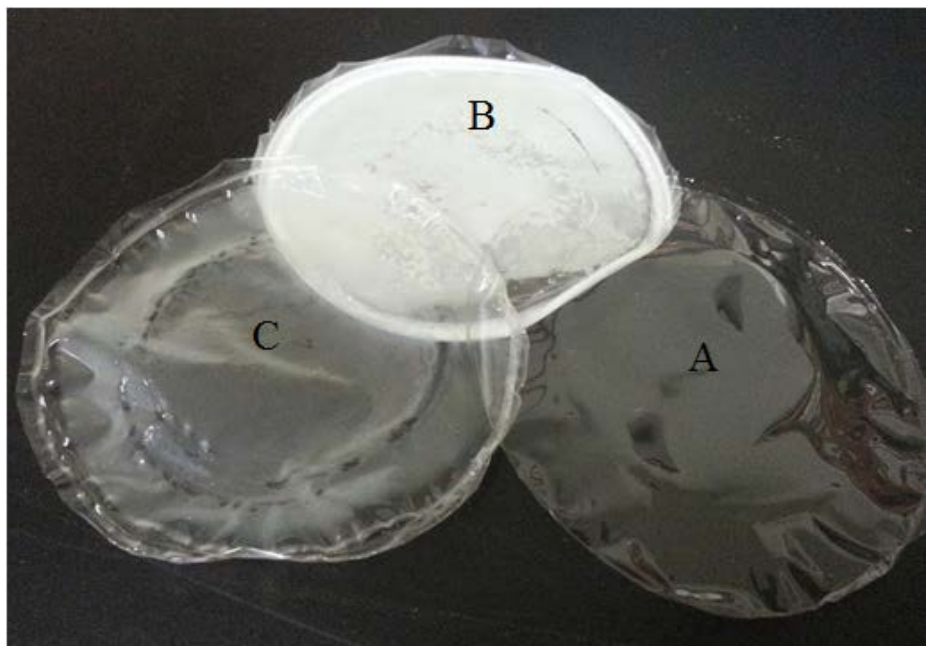

Figure 2. Chitosan films $1 \%$ without treatment (A), $\mathrm{NaOH}$ neutralized (B), $\mathrm{KOH}$ Neutralized (C). 


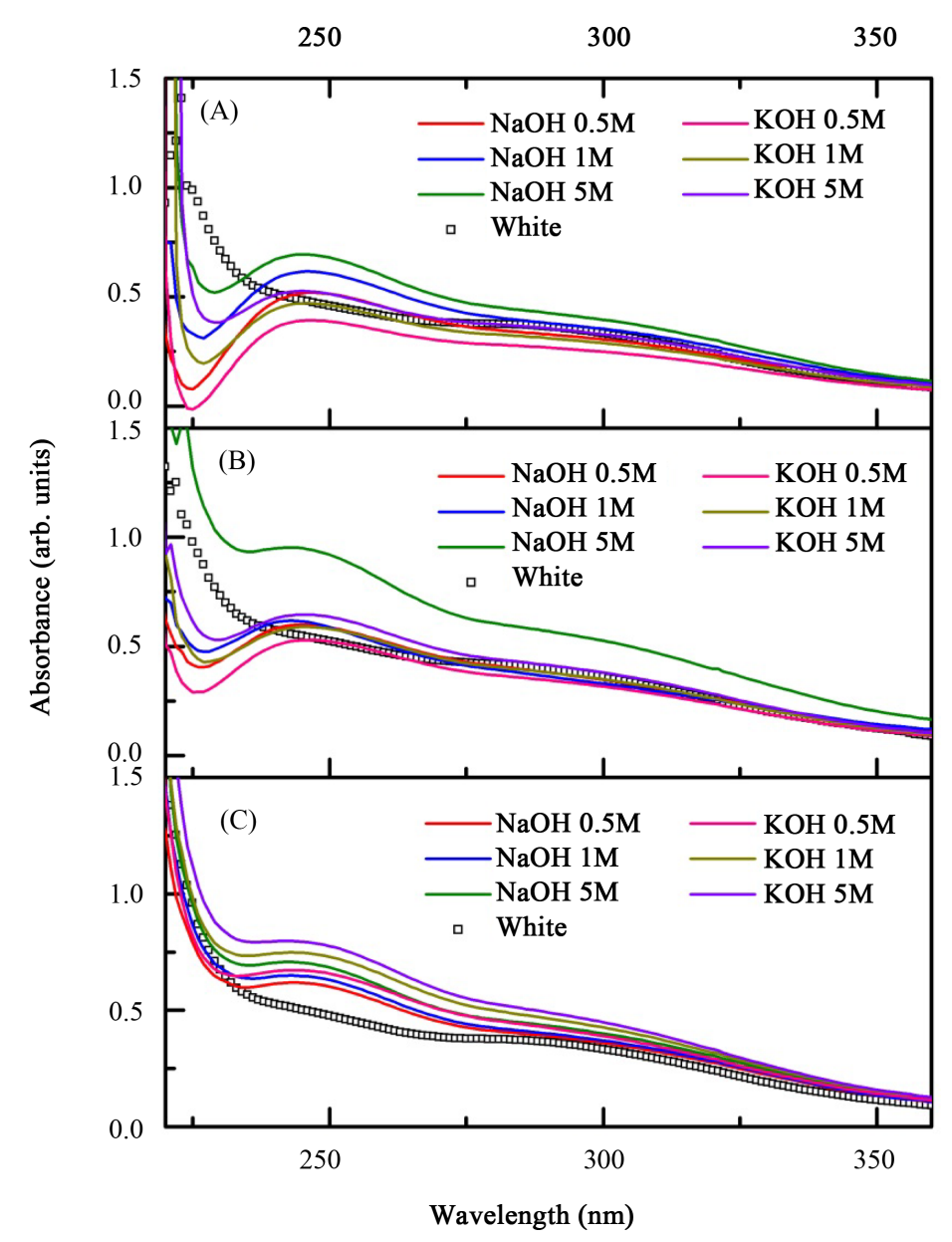

Figure 3. UV-vis Spectrum of solubilized chitosan by different concentrations of acetic acid, $1 \% \mathrm{p} / \mathrm{v}(\mathrm{A}), 0.8 \%(\mathrm{~B})$ and $0.5 \%(\mathrm{C})$ and neutralized with different bases concentrations.

\subsubsection{Spectroscopy Fourier Transform Infrared (FT-IR)}

The chitosan films showed characteristic bands at $3450 \mathrm{~cm}^{-1}$ (O-H stretching group), $3299 \mathrm{~cm}^{-1}$ (N-H stretching group), $2898 \mathrm{~cm}^{-1}$ (C-H stretching group), $1655 \mathrm{~cm}^{-1}$ (amide I band), $1560 \mathrm{~cm}^{-1}$ (amide II band, $\mathrm{N}-\mathrm{H}$ stretching), $1410 \mathrm{~cm}^{-1}$ (C-H asymmetric group and $\mathrm{CH}_{2}$ bending), $1310 \mathrm{~cm}^{-1}$ (amide III band), $1150 \mathrm{~cm}^{-1}$ (skeletal vibration involving the stretching bridge C-O-C) and $1080 \mathrm{~cm}^{-1}$ (skeletal vibration of pyranose chitosan structure) [15].

The spectra of the films obtained by solubilized chitosan with different concentration of acetic acid did not show differences in the characteristic peaks, as shown in Figure 4. However, it was observed that the reference peaks of chitosan are affected when the polycation is neutralized with $\mathrm{KOH}$ particularly in reference to those neutralized with $\mathrm{NaOH}$ and to films without treatment (Figure 5). Peaks of films neutralized with potassium exhibit a higher intensity compared to films neutralized with sodium, which in turn exhibit a higher intensity than films without treatment.

According to reported by [16] characteristic peaks for protonated amino groups $\left(\mathrm{NH}^{3+}\right)$ in the chitosan structure are near to $1588 \mathrm{~cm}^{-1}$, as a result is possible evaluate the degree of protonation of amine through the intensity of the peak as it appears on the FT-IR spectrum. In a similar manner, establishing the crystallinity degree of structure could be identified from the peak intensity $1410 \mathrm{~cm}^{-1}$, which shows stability vibration of the amorphous phase of amide III $\left(\mathrm{CH}_{2}\right)$ [17].

\subsubsection{X-Ray Diffraction}

According to [18] the crystal structure of chitosan is maintained primarily by intramolecular and intermolecular 


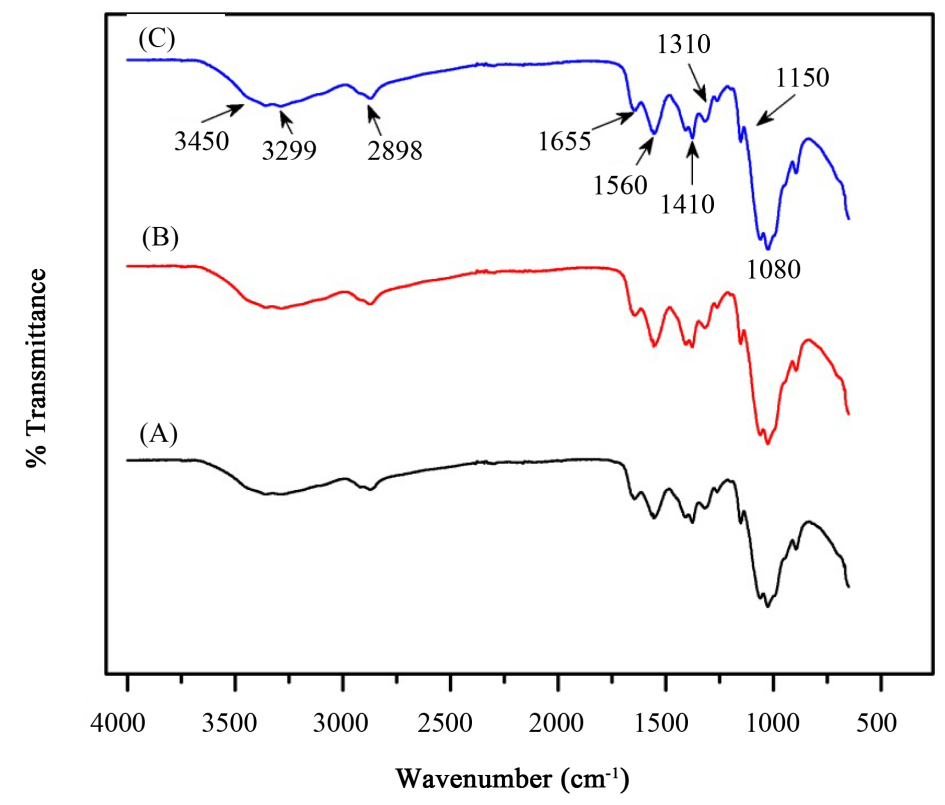

Figure 4. FT-IR chitosan $1 \%(\mathrm{p} / \mathrm{v})$ solubilized in acetic acid in concentrations (v/v) $1 \%(\mathrm{~A}) 0.8 \%(\mathrm{~B})$ and $0.5 \%(\mathrm{C})$.

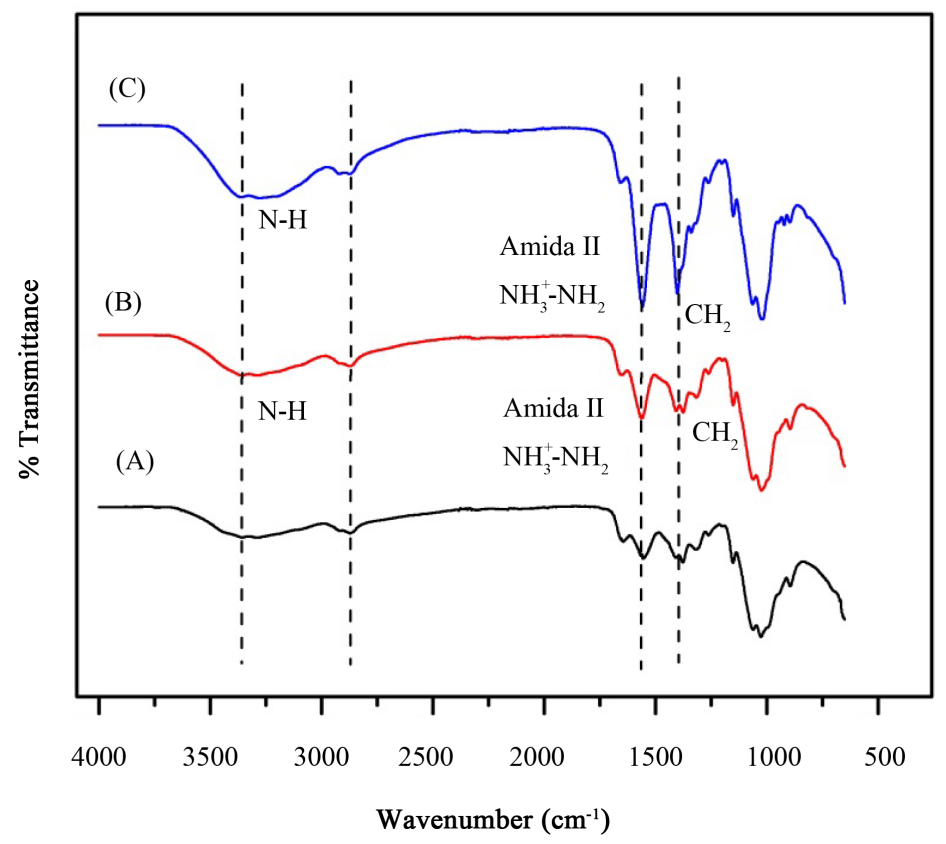

Figure 5. FT-IR chitosan $1 \%(\mathrm{p} / \mathrm{v})$ solubilized in acetic acid in concentration $1 \%(\mathrm{v} / \mathrm{v})$, film without treatment (A), Neutralized with $\mathrm{NaOH} 1 \mathrm{M}(\mathrm{B})$ and $\mathrm{KOH} 1 \mathrm{M}(\mathrm{C})$.

hydrogen bonding, established by an amino group at C-2 and a hydroxyl group at C-3, for the latter formed between two hydroxyl groups at C-6 and C-3, carbon positions on either side of an absorbed molecule of water.

Typically, chitosan membranes exhibit two characteristic peaks, which are related to two types of crystals that are present in the polymer matrix. The first peak has a strong reflection at $2 \theta=11.5^{\circ}$ and is cataloged as crystal I form with an orthorhombic configuration and having a unit cell of a = 7.76 $\AA, \mathrm{b}=10.91 \AA, \mathrm{c}=10.30 \AA, \beta=90^{\circ}$. The second peak has a reflection at $2 \theta=20.1^{\circ}$ associated with the crystal II form also with an orthorhombic 
configuration and a unit cell of $\mathrm{a}=4.4 \AA, \mathrm{b}=10.0 \AA, \mathrm{c}=10.30 \beta=90^{\circ}$ (the fiber axis). The size of the unit cell of the crystal I is bigger than the crystal II cell, due to the crystal I unit cell being constituted by two monomeric units along the main axis of the polymer chain, while the crystal II has only one monomeric unit along the principal axis [19].

The different concentrations of acetic acid have no influence on the formation of characteristic crystals in the chitosan membranes, presenting both characteristic peaks at $2 \theta=11.5^{\circ}$ and $2 \theta=20.1^{\circ}$.

The neutralizing process of chitosan polycation with sodium hydroxide and potassium hydroxide at concentrations of $0.5,1$ and $5 \mathrm{M}$ established a change in the conformity of the structure of crystal type I in the polymorph of chitosan. Figure 6(A) and Figure 6(B) shows the analysis of X-ray diffraction of neutralized chitosan membranes, showing a reduction of the peak $2 \theta=11.5^{\circ}$ which is characteristic of the hydrated part (tendon) in the chitosan polymeric structure of membranes [16]. According to reported previously [20] the modification of the peak related to the morphology of the crystal type I in the chitosan polymeric network structure is directly connected with the loss of hydrogen bonding and deprotonation of the amino groups in the chitosan polymer structure after the neutralization treatment.

\subsubsection{Thickness}

The average values of thickness after the neutralization process of chitosan polycationare shown in Figure 7. Film thickness was increased depending on the type of base used, exhibiting greater thickness for films neutralized with $\mathrm{KOH}$ in comparison with the films neutralized with $\mathrm{NaOH}$. The films neutralized with $\mathrm{NaOH}$ showed a thickness increase of $14 \%$ compared to films without treatment, while the films neutralized with $\mathrm{KOH}$ exhibited an increase of $68 \%$ with respect to films without treatment and a difference of $32 \%$ in relation to the film neutralized with $\mathrm{NaOH}$. The thickness increase is directly related to the possible formation of acetate. In the case of membranes obtained by polycation neutralization with sodium hydroxide, sodium acetate formed on the membrane surface, changing both color and thickness of the film; whereas the membranes obtained by chitosan polycation neutralization with potassium hydroxide showed a greater thickness compared to other films, because of the formation of acetate in the structure of the membrane. Similar results were reported by researchers who have established a significant increase in thickness after neutralization process, besides dopant incorporation inchitosan films [21]-[23].

\subsubsection{Swelling}

The resistance of polymers to high moisture environments is directly related to the presence of hydrophilic groups, cross-linking degree of the molecules and presence of ionic polar groups in the structure of chitosan films, which allow them to have a greater sensitivity to $\mathrm{pH}$ medium with which the films have an interaction [24].
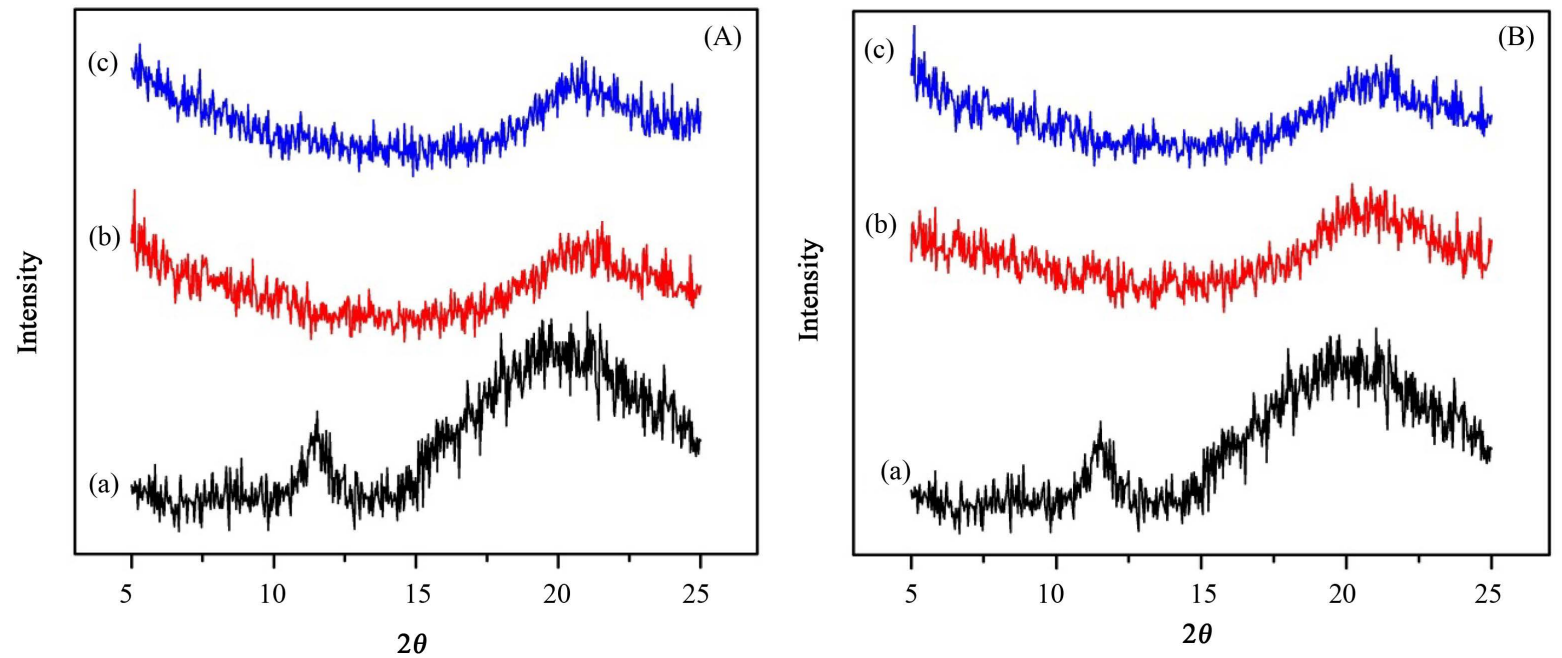

Figure 6. (A) XRD of neutralized chitosan by $0.5 \mathrm{M}$ of different bases; (a) without treatment, (b) $\mathrm{NaOH}$ and (c) $\mathrm{KOH}$. (B) XRD of neutralized chitosan by $\mathrm{KOH}$ in molar concentration of (a) without treatment, (b) $0.5 \mathrm{M}$ and (c) $5 \mathrm{M}$. 


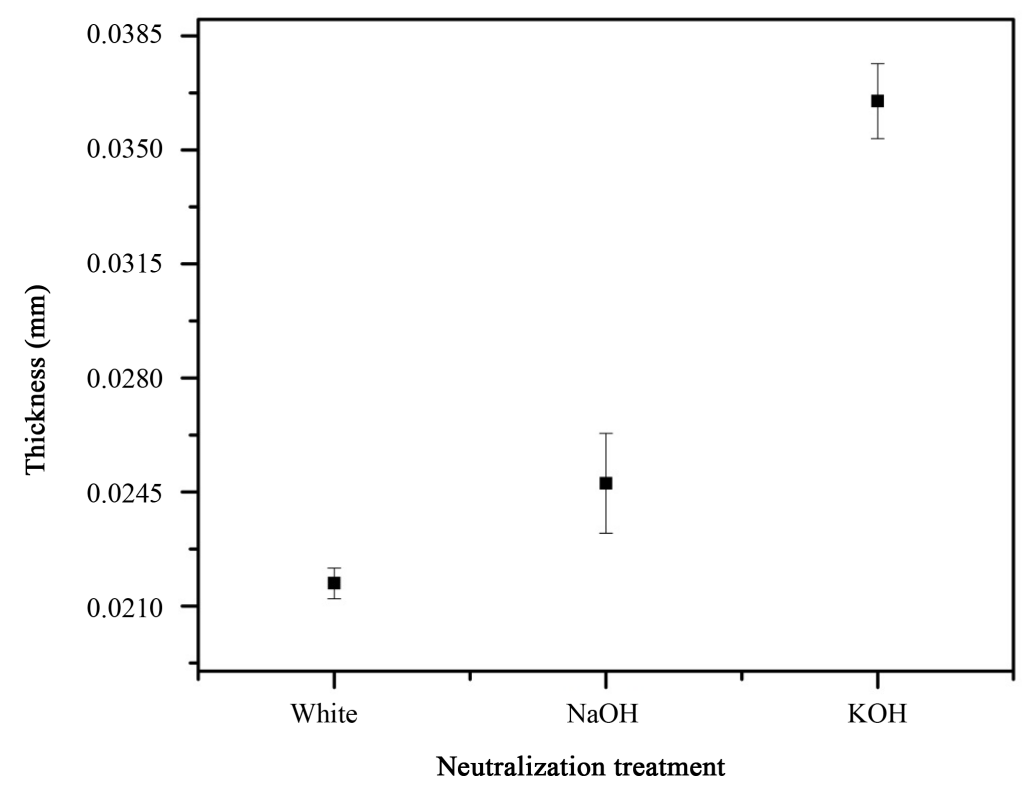

Figure 7. Thicknesses mean values of chitosan films in function of type and concentration of bases used in neutralized process.

Swelling evaluation in acidic and basic media allows the establishment of weight loss and gain of moisture in chitosan films after the neutralization process. The degree of swelling in the films was calculated from equation 1 and shown in Figure 8 and Figure 9.

Figure 8 shows the swelling of the neutralized chitosan films with $\mathrm{NaOH}$ at three different concentrations. They were immersed in a phosphate buffer solution at pHs of 5 and 9. After the initial weight gain due to moisture absorption in a less than three hours, the films tend to stabilize with time. The films without treatment exhibit a greater stability in relation to neutralized films, since the latter have two behaviors, an increasing curve due to moisture absorption and a decreasing standard attributed to weight loss during the stabilization of the films in buffer solution. The observed pattern is directly related to the dipping solution $\mathrm{pH}$, as well as the concentration and type of base used to neutralize the polycation. The neutralized films with $\mathrm{NaOH}$ showed moisture absorption and weight loss more stable over time for $5 \mathrm{M}$ concentrations.

Neutralized films with $\mathrm{KOH}$ and immersed in phosphate buffer $\mathrm{pH} 9$ showed a considerable mass loss in relation to the same samples immersed in phosphate buffer $\mathrm{pH}$ 5. Again this behavior can be explained in terms of electrostatic affinity between the aqueous medium and the modified chitosan structure, as the remaining potassium ions in the three-dimensional network of chitosan enable a high mass transfer between films and the reaction medium (Figure 9). Chitosan is a polysaccharide containing amino groups with pKa near to neutrality [24] therefore at $\mathrm{pH}<5.0$ the electrostatic repulsion between the protonated primary amino groups $\left(\mathrm{NH}_{3}^{+}\right)$exceeds the electrostatic interactions with the $\mathrm{COO}^{-}$groups, inducing the dissolution of the chitosan films without treatment.

\subsubsection{Mechanical Properties}

The mechanical properties such as tensile strength $(\sigma)$ (the maximum stress that the film can withstand, MPa), elongation at break $\left(\varepsilon_{\max }\right)$ (maximum variation of strain by the film before being broken, in \%); modulus of elasticity $\mathrm{E}$ (which is a measure of the stiffness of the film in MPa) and energy to break $\left(\mathrm{KJ} / \mathrm{m}^{2}\right.$ ) (energy required to break the film), were considered as the principal parameters of interest in this study and the results were summarized in Table 2.

The capacity of tensile strength is directly linked with the cohesive forces of the matrix polymer because of intermolecular interactions, and is affected by the concentration and type of base used in neutralization process [25].

The improvement of some mechanical characteristics in neutralized chitosan films as ductility is linked to the presence of bases and their different concentrations. Figure 10 shows the tensile strength of chitosan films 

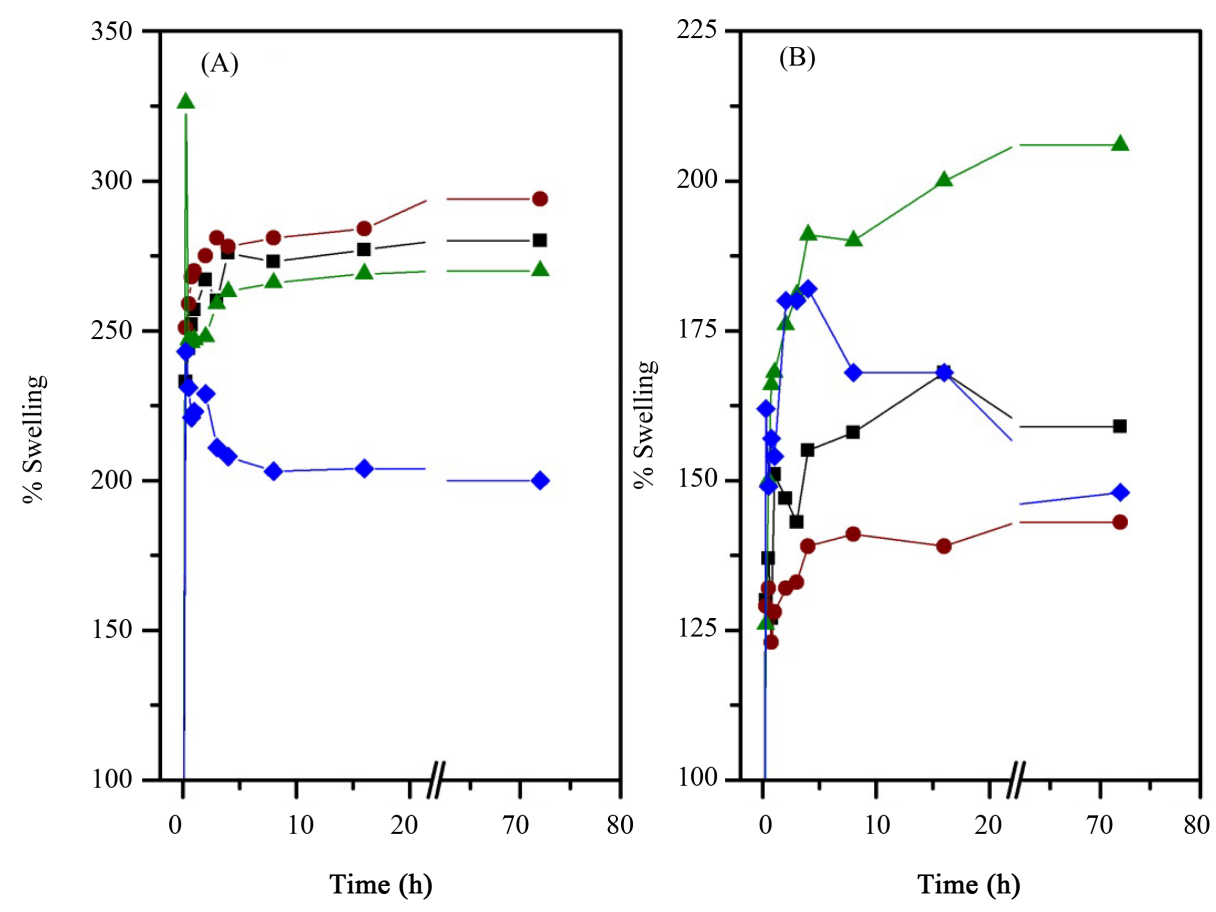

Figure 8. Swelling kinetics of neutralized chitosan films with $\mathrm{NaOH}$ into phosphate buffer pH5 (A) and phosphate buffer pH9 (B) at $37.5^{\circ} \mathrm{C}$ by $72 \mathrm{~h}$. (口) Qs W0, (०) QsSo0.5, ( $\left.\Delta\right)$ QsSo1.0, $(\diamond)$ QsSo5.0.
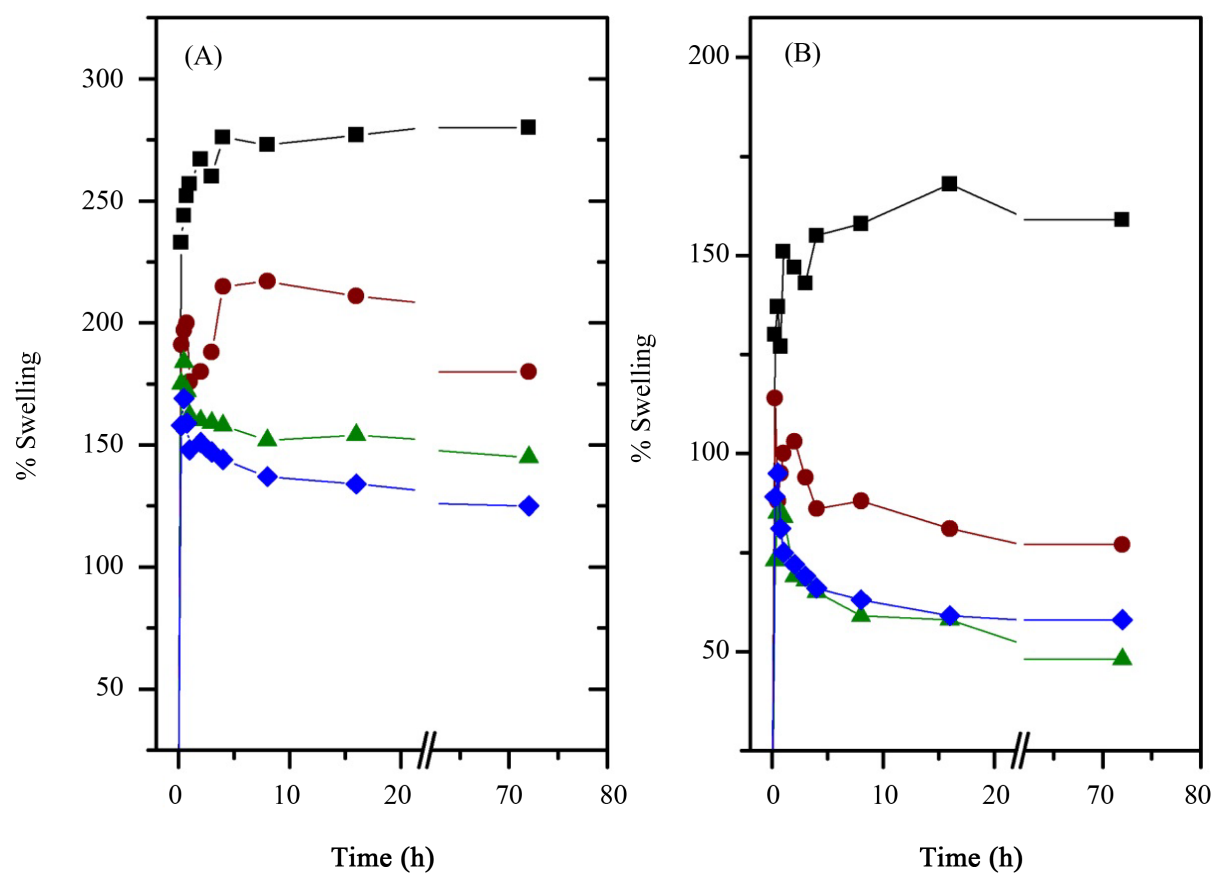

Figure 9. Swelling kinetics of neutralized chitosan films with $\mathrm{KOH}$ into phosphate buffer $\mathrm{pH} 5$ (A) and phosphate buffer pH9 (B) at $37.5^{\circ} \mathrm{C}$ by $72 \mathrm{~h}$. (口) Qs W0, (०) QsPo0.5, ( $\Delta$ ) QsPo1.0, ( $)$ QsPo5.0.

without and after the neutralization process, establishing that chitosan films by solubilized at a concentration of $0.5 \%$ of acetic acid and neutralized with potassium hydroxide at concentration of $0.5 \mathrm{M}$ exhibit greater resistance 


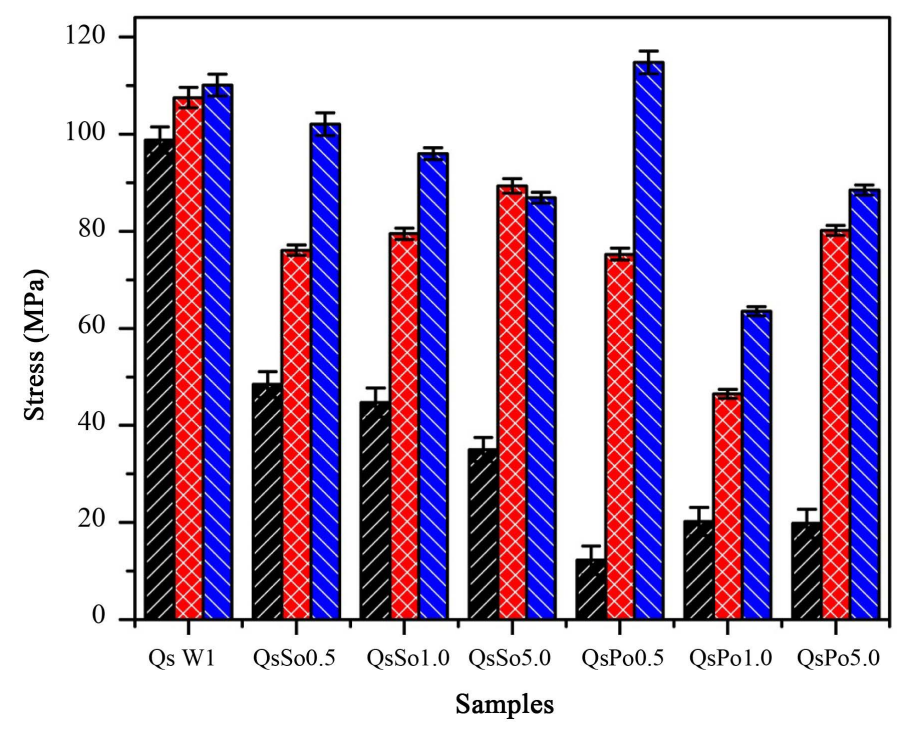

Figure 10. Comparison of tensile testing results of chitosan films without neutralizing (Qs W1) and neutralized films using $\mathrm{NaOH}$ and $\mathrm{KOH}$ at different concentrations, solubilized with acetic acid at concentrations of (//) $1 \%$, (x) $0.8 \%$, (II) $0.5 \%$.

Table 2. Mechanical properties of chitosan films after process of neutralization with $\mathrm{NaOH}$ and $\mathrm{KOH}$ bases.

\begin{tabular}{|c|c|c|c|c|}
\hline $\begin{array}{l}\text { Codification of } \\
\text { samples }\end{array}$ & Tensile strength $(\sigma)(\mathrm{MPa})$ & Elongation at break $(\varepsilon)(\%)$ & $\begin{array}{l}\text { Elastic Modulus (E) } \\
(\mathrm{MPa})\end{array}$ & $\begin{array}{l}\text { Energy to break } \\
\qquad\left(\mathrm{KJ} / \mathrm{m}^{2}\right)\end{array}$ \\
\hline $\mathrm{Qs}_{\mathrm{W} 1}$ & $98.82 \pm 0.72$ & $6.28 \pm 0.07$ & $2442.61 \pm 198.63$ & $195.371 \pm 17.45$ \\
\hline $\mathrm{QsSo}_{1} 0.5$ & $48.43 \pm 0.68$ & $2.48 \pm 0.07$ & $2463.02 \pm 185.32$ & $25.907 \pm 4.54$ \\
\hline $\mathrm{QsSo}_{1} 1.0$ & $44.74 \pm 0.98$ & $2.17 \pm 0.09$ & $2658.67 \pm 219.63$ & $20.864 \pm 3.58$ \\
\hline $\mathrm{QsSo}_{1} 5.0$ & $35.02 \pm 0.51$ & $1.74 \pm 0.05$ & $3076.93 \pm 275.53$ & $11.559 \pm 2.21$ \\
\hline $\mathrm{QsPo}_{1} 0.5$ & $12.25 \pm 0.95$ & $3.68 \pm 0.07$ & $660.52 \pm 89.63$ & $14.433 \pm 1.08$ \\
\hline $\mathrm{QsPo}_{1} 1.0$ & $20.22 \pm 0.85$ & $6.45 \pm 0.09$ & $807.79 \pm 97.45$ & $45.643 \pm 3.45$ \\
\hline $\mathrm{QsPo}_{1} 5.0$ & $19.82 \pm 0.94$ & $6.49 \pm 0.07$ & $816.14 \pm 92.85$ & $44.918 \pm 2.18$ \\
\hline $\mathrm{Qs}_{\mathrm{W} 2}$ & $107.55 \pm 2.11$ & $6.42 \pm 0.02$ & $3374.35 \pm 212.28$ & $239.737 \pm 19.87$ \\
\hline $\mathrm{QsSO}_{2} 0.5$ & $76.1 \pm 1.08$ & $2.25 \pm 0.03$ & $4329.78 \pm 282.81$ & $39.637 \pm 1.45$ \\
\hline $\mathrm{QsSO}_{2} 1.0$ & $79.5 \pm 1.17$ & $3.73 \pm 0.02$ & $3597.5 \pm 231.78$ & $83.865 \pm 4.85$ \\
\hline $\mathrm{QsSo}_{2} 5.0$ & $89.34 \pm 1.51$ & $4.1 \pm 0.02$ & $3265.4 \pm 210.48$ & $101.022 \pm 9.77$ \\
\hline $\mathrm{QsPo}_{2} 0.5$ & $75.28 \pm 1.23$ & $2.72 \pm 0.05$ & $3578.15 \pm 222.22$ & $44.054 \pm 1.54$ \\
\hline $\mathrm{QsPo}_{2} 1.0$ & $46.51 \pm 0.95$ & $4.34 \pm 0.04$ & $2031.49 \pm 182.28$ & $68.573 \pm 2.87$ \\
\hline $\mathrm{QsPo}_{2} 5.0$ & $80.16 \pm 1.03$ & $3.99 \pm 0.09$ & $3535.9 \pm 242.44$ & $86.524 \pm 3.24$ \\
\hline $\mathrm{Qs}_{\mathrm{W} 3}$ & $110.11 \pm 2.23$ & $4.72 \pm 0.04$ & $3291.74 \pm 187.91$ & $154.28 \pm 4.69$ \\
\hline $\mathrm{QsSo}_{3} 0.5$ & $102.12 \pm 2.35$ & $4.5 \pm 0.05$ & $3878.32 \pm 198.15$ & $136.069 \pm 4.84$ \\
\hline $\mathrm{QsSo}_{3} 1.0$ & $96.02 \pm 1.23$ & $4.55 \pm 0.03$ & $3962.47 \pm 201.11$ & $136.183 \pm 4.12$ \\
\hline $\mathrm{QsSo}_{3} 5.0$ & $86.92 \pm 1.12$ & $5.42 \pm 0.04$ & $4083.23 \pm 231.35$ & $174.576 \pm 5.14$ \\
\hline $\mathrm{QsPo}_{3} 0.5$ & $114.83 \pm 2.34$ & $3.62 \pm 0.08$ & $4464.65 \pm 242.91$ & $119.187 \pm 3.87$ \\
\hline $\mathrm{QsPo}_{3} 1.0$ & $63.54 \pm 0.93$ & $2.64 \pm 0.09$ & $3217.24 \pm 211.51$ & $37.281 \pm 2.69$ \\
\hline $\mathrm{QsPo}_{3} 5.0$ & $88.49 \pm 1.03$ & $2.76 \pm 0.04$ & $3974.87 \pm 271.08$ & $61.092 \pm 3.01$ \\
\hline
\end{tabular}

Data followed by their standard errors. 
to strain. Similar results were obtained by [26] in stress test and the results attested to an improvement in ductility of the material due to the porosity of the membrane made by small crystals of $\mathrm{KOH}$ remaining in the chitosan films. Figure 11 shows the strain of neutralized film, showing that the samples neutralized with KOH have a higher strain compared with samples neutralized with $\mathrm{NaOH}$ and without treatment samples. [27] Assert that, the use of plasticizers in chitosan films increase the ductility of the material, reducing the tensile strength and increasing elongation of the membrane. In Figure 10, can be seen that the samples solubilized with acetic acid at $1 \%$ and neutralized with $\mathrm{KOH} 1 \mathrm{M}$ and $5 \mathrm{M}$ have the lowest tensile strength, whereas in Figure 11 these same samples show higher elongation percentage, which can be attributed to possibility of $\mathrm{KOH}$ have a plasticizing capacity in chitosan films.

The neutralization process leads to structural changes in the chitosan chains, which have impact on the physical characteristics such as the elastic modulus (Young) and energy $\left(\mathrm{KJ} / \mathrm{m}^{2}\right)$ required for rupture. The results show that the membranes neutralized with $\mathrm{NaOH}$ exhibit an increase in elastic modulus compared to membranes neutralized with $\mathrm{KOH}$. At the same time, membranes neutralized with $\mathrm{NaOH}$ have a lower deformation compared to membranes neutralized with KOH (Table 2); [26] obtained similar results, which established that the modulus of elasticity and the energy needed to break the membranes decrease with the presence of $\mathrm{KOH}$ within the membrane. However, [16] obtained an increase in the elasticity modulus in membranes neutralized with $\mathrm{NaOH}$. Based on the analysis it is clear that the films neutralized with $\mathrm{NaOH}$ exhibit a fragile behavior whereas films neutralized with $\mathrm{KOH}$ exhibit a ductile behavior.

\subsubsection{Scanning Electron Microscopy}

The surfaces of the membranes without neutralization (Figure 12(A)) exhibit a regularity and uniformity, which is linked to the drying process. The morphology of the fracture (Figure 12(B)) shows a homogeneous, dense and cohesive structure, typical of chitosan films without any processing [25].

The membranes obtained after neutralization show changes such as the presence of crystals of sodium and potassium on the surface (Figures 13(A)-(D)). Furthermore the cross section of the membrane after fracture exhibits changes, such as the presence of pores and laminar formats (Figure 14(A) and Figure 14(D)), when compared to films without neutralizer which exhibit a dense and cohesive morphology (Figure 12(A)). These microstructural changes are the reason there were also significant changes in the mechanical properties compared to films without treatment.

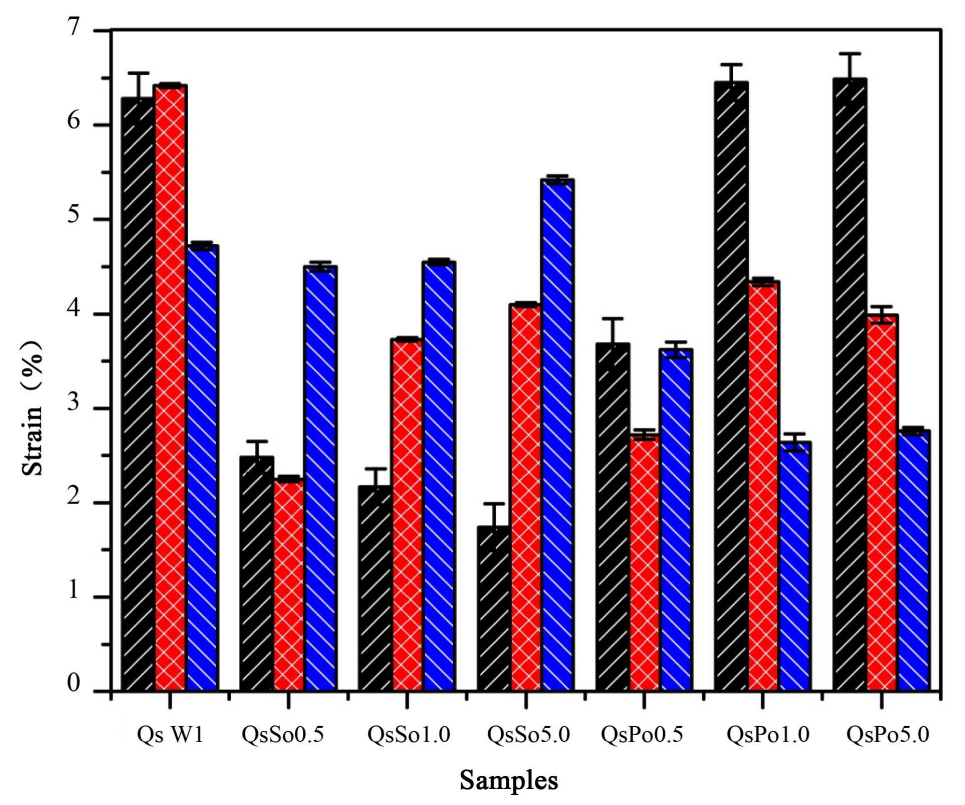

Figure 11. Comparison of strain results of chitosan films without neutralizing (Qs W1) and neutralized films using $\mathrm{NaOH}$ and $\mathrm{KOH}$ at different concentrations, solubilized with acetic acid at concentrations of $(/ /) 1 \%,(\mathrm{x})$ $0.8 \%$, (II) $0.5 \%$. 

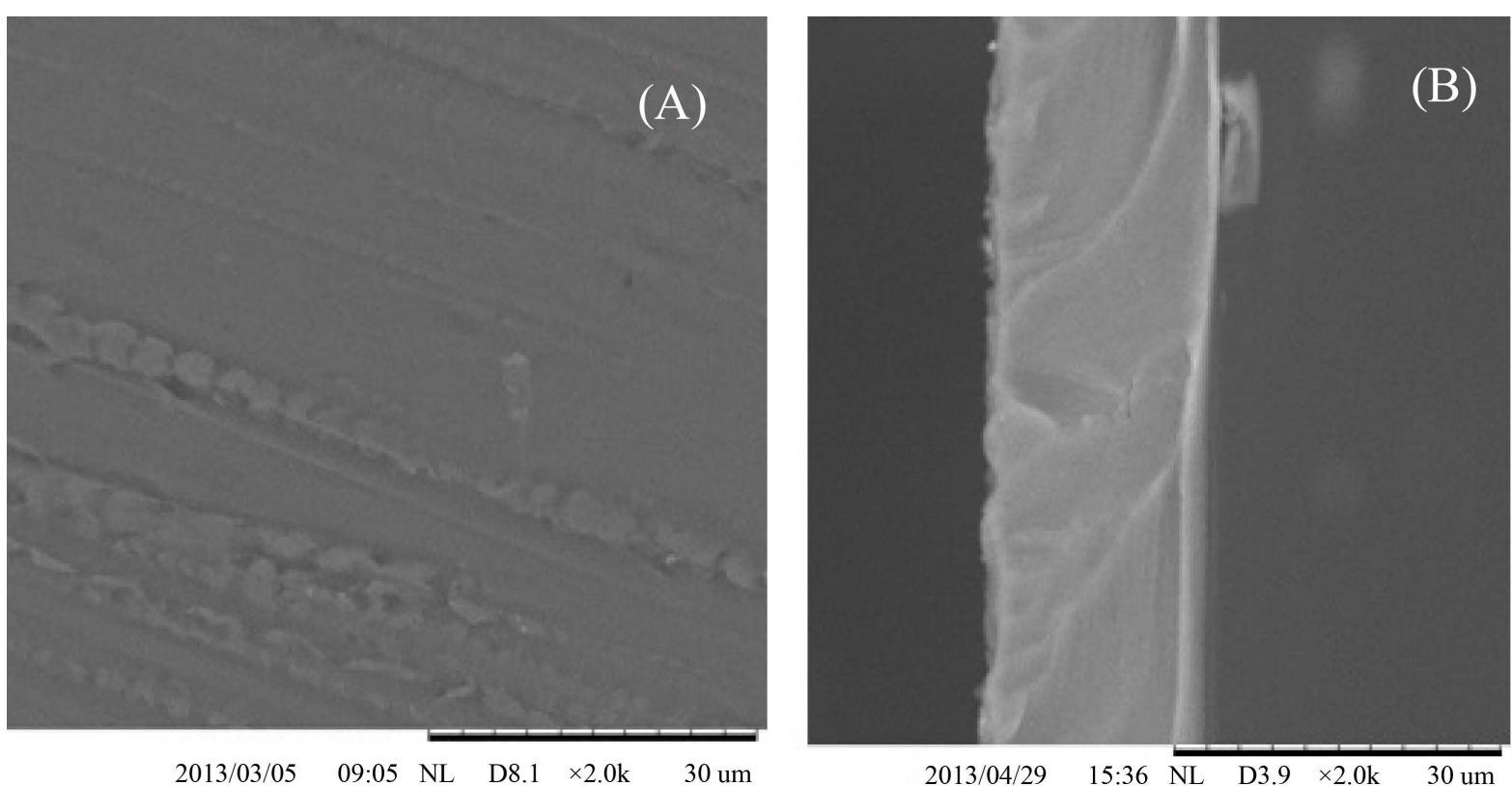

2013/03/05

09:05 NL $\quad$ D8.1 $\times 2.0 \mathrm{k}$

30 um

2013/04/29

Figure 12. SEM of chitosan films without neutralizing process: (A) membrane surface, (B) cross section of fracture.
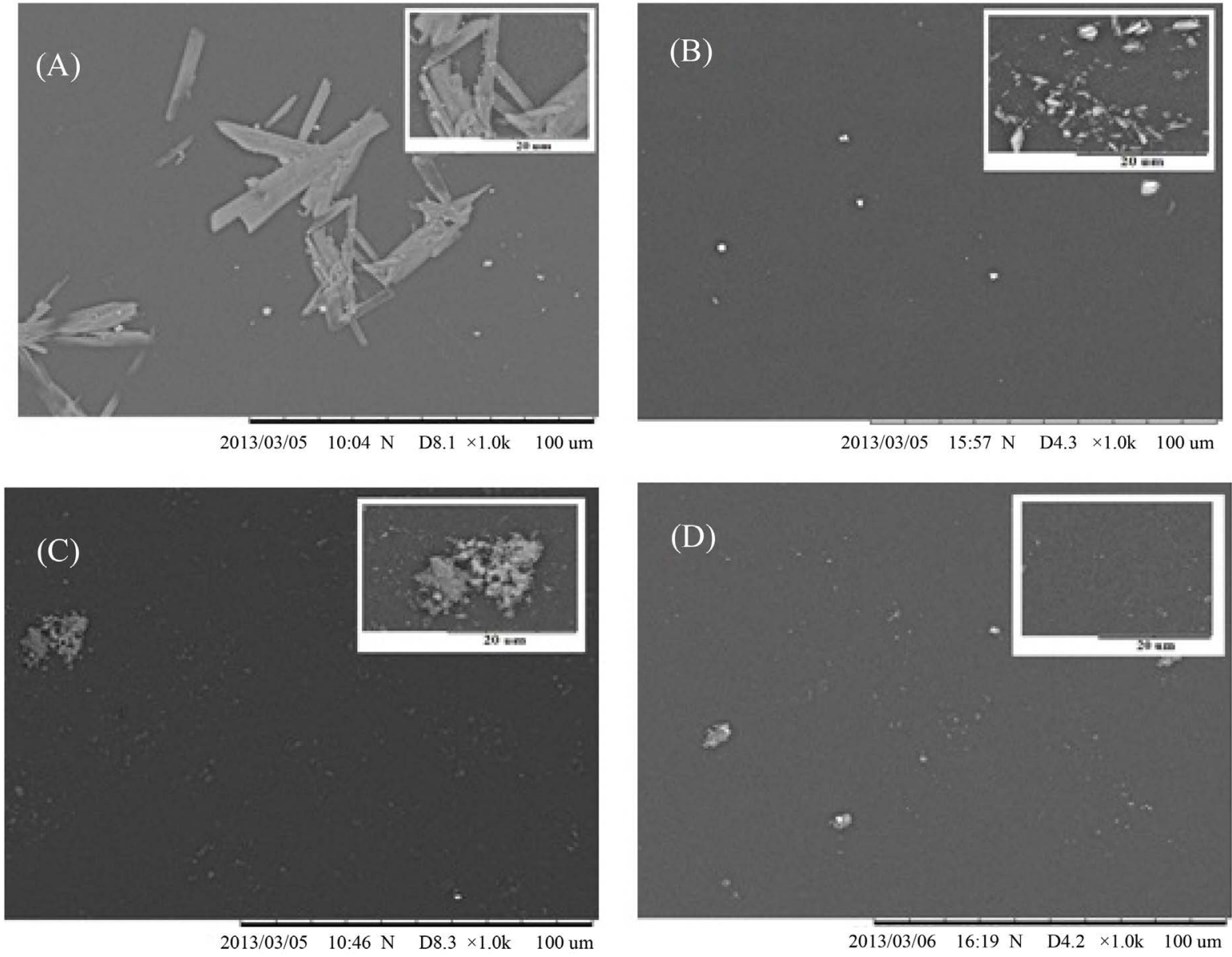

Figure 13. SEM by chitosan films surface solubilize with acetic acid $1 \%$ (A) and (C) and $0.5 \%$ (B) and (D); neutralized with $\mathrm{NaOH} 0.5 \mathrm{M}(\mathrm{A})$ and (B) and $\mathrm{KOH} 0.5 \mathrm{M}(\mathrm{C})$ and (D). 

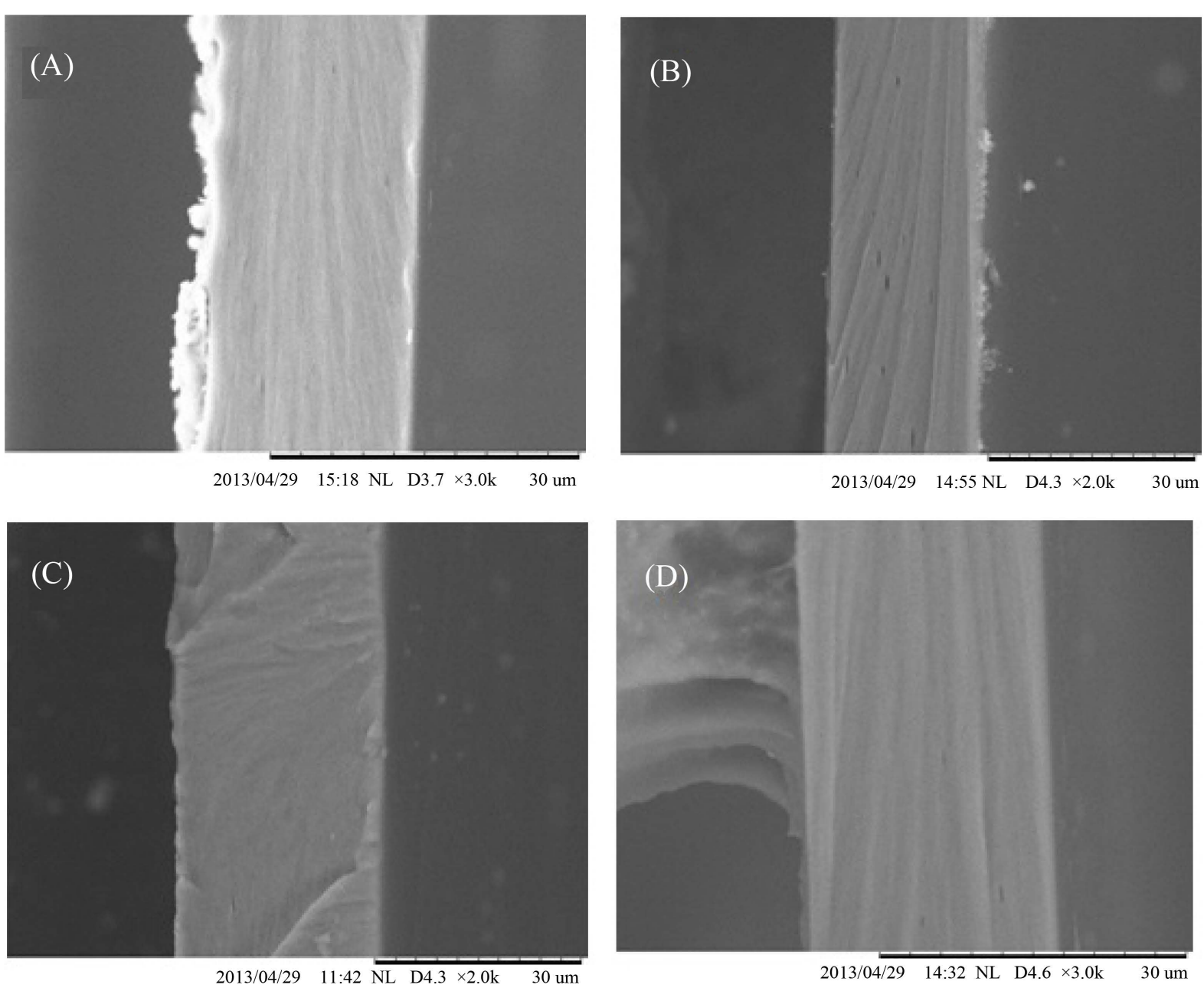

Figure 14. SEM of cross section after to break of chitosan films solubilized with acetic acid $1 \%$ (A) and (C) and $0.5 \%$ (B) and (D) neutralized with $\mathrm{NaOH} 0.5 \mathrm{M}(\mathrm{A})$ and (B) and $\mathrm{KOH} 0.5 \mathrm{M}(\mathrm{C})$ and (D).

\section{Conclusions}

The neutralization process of chitosan polycation to $\mathrm{pH} 6.0$ by the drip method of bases did not show precipitation of chitosan. Additionally, different concentrations of acetic acid did not present significant difference to the physicochemical properties of chitosan membranes.

The use of strong bases such as $\mathrm{NaOH}$ and $\mathrm{KOH}$ caused several changes to the membrane (conformity of crystals, increase in the thickness, high capacity to retain moisture and variation in the mechanical properties of the films). These results from the methodology were used in the neutralization of the chitosan polycation, which allowed for the creation of membranes with favorable characteristics for the development of matrices for biosensors or load cells, due to the presence of sodium or potassium ions in the polymer structure.

\section{Acknowledgements}

The authors gratefully acknowledge the financial support from "Coordenação de aperfeiçoamento de pessoal de nivel superior CAPES" and the laboratories of Chemistry Biology, Biosensors and Biomaterials and Food Technology laboratory, from the Animal Science and Food Engineering College, University of São Paulo.

\section{References}

[1] Akkılıç, K., Uzun, I. and Kılıçoğlu, T. (2007) The Calculation of Electronic Properties of an Ag/chitosan/n-Si Schottky Barrier Diode. Synthetic Metals, 157, 297-302. http://dx.doi.org/10.1016/j.synthmet.2007.03.009 
[2] Croisier, F. and Jérôme C. (2013) Chitosan-Based Biomaterials for Tissue Engineering. European Polymer Journal, 49, 780-792. http://dx.doi.org/10.1016/j.eurpolymj.2012.12.009

[3] Giri, T.K., Thakur, A., Alexander, A., Badwaik, H. and Tripathi, D.K. (2012) Modified Chitosan Hydrogels as Drug Delivery and Tissue Engineering Systems: Present Status and Applications. Acta Pharmaceutica Sinica B, 2, 439-449. http://dx.doi.org/10.1016/j.apsb.2012.07.004

[4] Park, J.H., Saravanakumar, G., Kim, K. and Kwon, I.C. (2010) Targeted Delivery of Low Molecular Drugs Using Chitosan and Its Derivatives. Advanced Drug Delivery Reviews, 62, 28-41. http://dx.doi.org/10.1016/j.addr.2009.10.003

[5] Bernkop-Schnürch, A. and Dünnhaupt, S. (2012) Chitosan-Based Drug Delivery Systems. European Journal of Pharmaceutics and Biopharmaceutics, 81, 463-469. http://dx.doi.org/10.1016/j.ejpb.2012.04.007

[6] Rinaudo, M. (2006) Chitin and Chitosan: Properties and Applications. Progress in Polymer Science, 31, 603-632. http://dx.doi.org/10.1016/j.progpolymsci.2006.06.001

[7] Schmidt, T.F., Caseli, L., dos Santos, D.S. and Oliveira, O.N. (2009) Enzyme Activity of Horseradish Peroxidase Immobilized in Chitosan Matrices in Alternated Layers. Materials Science and Engineering: C, 29, 1889-1892. http://dx.doi.org/10.1016/j.msec.2009.02.020

[8] Valencia, G.A. (2013) Transporte eletrônico em biofilmes nanoestruturados para biossensores a base de enzimas. Universidade de São Paulo, 122. http://www.teses.usp.br/teses/disponiveis/74/74132/tde-10072013-095546/pt-br.php

[9] Noriega, S.E. and Subramanian, A. (2011) Consequences of Neutralization on the Proliferation and Cytoskeletal Organization of Chondrocytes on Chitosan-Based Matrices. International Journal of Carbohydrate Chemistry, 2011, Article ID: 809743. http://dx.doi.org/10.1155/2011/809743

[10] Tanuma, H., Saito, T., Nishikawa, K., Dong, T., Yazawa, K. and Inoue, Y. (2010) Preparation and Characterization of PEG-Cross-Linked Chitosan Hydrogel Films with Controllable Swelling and Enzymatic Degradation Behavior. Carbohydrate Polymers, 80, 260-265. http://dx.doi.org/10.1016/j.carbpol.2009.11.022

[11] Boeris, V., Micheletto, Y., Lionzo, M., Da Silveira, N.P. and Picó, G. (2011) Interaction Behavior between Chitosan and Pepsin. Carbohydrate Polymers, 84, 459-464. http://dx.doi.org/10.1016/j.carbpol.2010.12.008

[12] Vicentini, N.M., Dupuy, N., Leitzelman, M., Cereda, M.P. and Sobral, P.J.A. (2005) Prediction of Cassava Starch Edible Film Properties by Chemometric Analysis of Infrared Spectra. Spectroscopy Letters, 38, 749-767. http://dx.doi.org/10.1080/00387010500316080

[13] Bonilla, J., Fortunati, E., Atarés, L., Chiralt, A. and Kenny, J.M. (2014) Physical, Structural and Antimicrobial Properties of Poly Vinyl Alcohol-Chitosan Biodegradable Films. Food Hydrocolloids, 35, 463-470. http://dx.doi.org/10.1016/j.foodhyd.2013.07.002

[14] Abdelrazek, E.M., Elashmawi, I.S. and Labeeb, S. (2010) Chitosan Filler Effects on the Experimental Characterization, Spectroscopic Investigation and Thermal Studies of PVA/PVP Blend Films. Physica B: Condensed Matter, 405, 20212027. http://dx.doi.org/10.1016/j.physb.2010.01.095

[15] Singh, J. and Dutta, P.K. (2009) Preparation, Circular Dichroism Induced Helical Conformation and Optical Property of Chitosan Acid Salt Complexes for Biomedical Applications. International Journal of Biological Macromolecules, 45, 384-392. http://dx.doi.org/10.1016/j.ijbiomac.2009.07.004

[16] He, Q., Ao, Q., Gong, Y. and Zhang, X. (2011) Preparation of Chitosan Films Using Different Neutralizing Solutions to Improve Endothelial Cell Compatibility. Journal of Materials Science: Materials in Medicine, 22, 2791-2802. http://dx.doi.org/10.1007/s10856-011-4444-y

[17] Pucić, I. and Jurkin, T. (2012) FTIR Assessment of Poly(ethylene oxide) Irradiated in Solid State, Melt and Aqeuous Solution. Radiation Physics and Chemistry, 81, 1426-1429. http://dx.doi.org/10.1016/j.radphyschem.2011.12.005

[18] Wan, Y., Creber, K.A.M., Peppley, B. and Tam Bui, V. (2006) Chitosan-Based Solid Electrolyte Composite Membranes: I. Preparation and Characterization. Journal of Membrane Science, 280, 666-674. http://dx.doi.org/10.1016/j.memsci.2006.02.024

[19] Lima, C.G.A., de Oliveira, R.S., Figueiró, S.D., Wehmann, C.F., Góes, J.C. and Sombra, A.S.B. (2006) DC Conductivity and Dielectric Permittivity of Collagen-Chitosan Films. Materials Chemistry and Physics, 99, 284-288. http://dx.doi.org/10.1016/j.matchemphys.2005.10.027

[20] Zong, Z., Kimura, Y., Takahashi, M. and Yamane, H. (2000) Characterization of Chemical and Solid State Structures of Acylated Chitosans. Polymer, 41, 899-906. http://dx.doi.org/10.1016/S0032-3861(99)00270-0

[21] Thakhiew, W., Devahastin, S. and Soponronnarit, S. (2013) Physical and Mechanical Properties of Chitosan Films as Affected by Drying Methods and Addition of Antimicrobial Agent. Journal of Food Engineering, 119, 140-149. http://dx.doi.org/10.1016/j.jfoodeng.2013.05.020

[22] Khoshgozaran-Abras, S., Azizi, M.H., Hamidy, Z. and Bagheripoor-Fallah, N. (2012) Mechanical, Physicochemical 
and Color Properties of Chitosan Based-Films as a Function of Aloe Vera Gel Incorporation. Carbohydrate Polymers, 87, 2058-2062. http://dx.doi.org/10.1016/j.carbpol.2011.10.020

[23] Campos, M.G.N., Grosso, C.R.F., Cárdenas, G. and Mei, L.H.I. (2005) Effects of Neutralization Process on Preparation and Characterization of Chitosan Membranes for Wound Dressing. Macromolecular Symposia, 229, 253-257. http://dx.doi.org/10.1002/masy.200551131

[24] Tasselli, F., Mirmohseni, A., Seyed Dorraji, M.S. and Figoli, A. (2013) Mechanical, Swelling and Adsorptive Properties of Dry-Wet Spun Chitosan Hollow Fibers Crosslinked with Glutaraldehyde. Reactive and Functional Polymers, 73, 218-223. http://dx.doi.org/10.1016/j.reactfunctpolym.2012.08.007

[25] Bonilla, J., Atarés, L., Vargas, M. and Chiralt, A. (2013) Properties of Wheat Starch Film-Forming Dispersions and Films as Affected by Chitosan Addition. Journal of Food Engineering, 114, 303-312. http://dx.doi.org/10.1016/j.jfoodeng.2012.08.005

[26] Wan, Y., Creber, K.A.M., Peppley, B. and Bui, V.T. (2006) Chitosan-Based Electrolyte Composite Membranes II. Mechanical Properties and Ionic Conductivity. Journal of Membrane Science, 284, 331-338. http://dx.doi.org/10.1016/j.memsci.2006.07.046

[27] Azevedo, E.P., Saldanha, T.D.P., Navarro, M.V.M., Medeiros, A.C., Ginani, M.F. and Raffin, F.N. (2006) Mechanical Properties and Release Studies of Chitosan Films Impregnated with Silver Sulfadiazine. Journal of Applied Polymer Science, 102, 3462-3470. http://dx.doi.org/10.1002/app.24537 